Portland State University

PDXScholar

$1-1-2005$

\title{
Marine Ice Modification of Fringing Ice Shelf Flow
}

\author{
Christina L. Hulbe \\ Portland State University \\ R. Johnston \\ Portland State University \\ Ian R. Joughin \\ University of Washington - Seattle Campus \\ Ted A. Scambos \\ University of Colorado at Boulder
}

Follow this and additional works at: https://pdxscholar.library.pdx.edu/geology_fac

Part of the Geology Commons

Let us know how access to this document benefits you.

\section{Citation Details}

Hulbe, C.L., R. Johnston, I. Joughin, T. Scambos, 2005, Marine ice modification of fringing ice shelf flow. Arctic, Antarctic, and Alpine Research, 37 (3), 323-330.

This Article is brought to you for free and open access. It has been accepted for inclusion in Geology Faculty Publications and Presentations by an authorized administrator of PDXScholar. Please contact us if we can make this document more accessible: pdxscholar@pdx.edu. 


\section{Marine Ice Modification of Fringing Ice Shelf Flow}

\author{
C. L. Hulbe* \\ R. Johnston* \\ I. Joughin† and \\ T. Scambos \\ *Portland State University, \\ Department of Geology, Portland, \\ OR 97207-0751, U.S.A. \\ chulbe@pdx.edu \\ $\dagger$ Applied Physics Laboratory, University of \\ Washington, Seattle, WA 98105, U.S.A. \\ $\ddagger$ National Snow and Ice Data Center, \\ University of Colorado, Boulder, \\ CO 80309, U.S.A.
}

\begin{abstract}
Locally derived ice is often observed to fill through-cutting rifts and uneven fronts in ice shelves. That ice may nucleate as fast ice at the shelf front, by growth at the sea surface within rifts, or by basal accretion. Here, we investigate the role of such ice in the flow of the Brunt Ice Shelf and adjacent Stancomb-Wills ice tongue, along the Caird Coast of Antarctica. Much of the shelf system is severely rifted, with locally derived ice filling the space between rift walls and around ice rafts. A series of numerical experiments that account for thermal properties of the different ices is used to investigate the influence of that mixture of sea and marine ice on the kinematics and dynamics of the shelf system. The simulations are constrained by a variety of satellite remote-sensing data. We find that the locally derived ice forms a dynamic connection between the ice tongue and the Caird Coast, effectively creating an embayment where no coastal embayment exists. This may have implications for the expansion of ice shelves along arctic coasts during past glaciations.
\end{abstract}

\section{Introduction}

The geometry and flow field of an ice shelf are determined largely by the geometry of the coastline along which the shelf floats (Sanderson, 1979; Thomas, 1979). This is because in the absence of basal traction, the gravitational driving stress must be balanced by stresses acting at the margins of the shelf: adjacent coasts, the perimeters of ice rises, and the seaward front. Deeply embayed ice shelves experience substantial lateral drag, while ice tongues experience nearly none. In the case of the Stancomb-Wills ice tongue and adjacent Brunt Ice Shelf, an approximately $29 \times 10^{3} \mathrm{~km}^{2}$ peripheral ice shelf system in the eastern Weddell Sea (Figs. 1 and 2), coastal boundaries and pinning points are few. The result is very rapid ice-shelf flow, severe rifting, and an interesting dynamic interplay among ices of distinctly different origins.

The Brunt Ice Shelf system (the shelf and adjacent StancombWills ice tongue) is composed of ices with different origins that appear to flow as a dynamically coherent unit (see also Rignot, 2002). Here, we simplify the text by using the term meteoric to represent all ice derived from land and the term marine to represent ice newly formed near the ocean surface. The marine ice must in reality be a combination of sea ice formed at the ocean surface, marine ice accreted below it, and firn atop the sea ice layer. Marine-ice accretion would be driven by the rapid rise of fresh, cold meltwater from the base of relatively thick meteoric ice up into adjacent rifts (Bombosch and Jenkins, 1995). We estimate, based on remotely sensed surface elevation and imagery, that between $20 \%$ and $30 \%$ of the shelf area is marine ice.

For the purpose of this discussion, we divide the shelf into three distinct morphologic provinces, as observed via satellite remote sensing. Thomas (1973) describes these provinces in some detail. The easternmost sector of the Brunt Ice Shelf is fed by the outflow of Stancomb-Wills Glacier ("Dalgliesh Glacier" in Thomas, 1973). The Stancomb-Wills ice tongue is heavily rifted on both lateral margins, and on both sides the rifts are marine-ice filled. The right-lateral margin is confined by Lyddan Island and the Riiser-Larsen Ice Shelf. Southwest of Stancomb-Wills ice tongue is a region of large, widely spaced ice rafts embedded in what at present is a thick marine ice layer. The westernmost sector of the shelf is more finely dissected. Near the grounding line, narrow wedges of calved meteoric ice are suspended in marine ice. Over time, the space between calved blocks fills with wind-blown snow. The McDonald ice rumples provide backstress to this region of the shelf and produce near-field compression ridges in the ice (Thomas, 1973). Hereafter, we refer to these three areas as the Stancomb-Wills, ice-raft, and Halley Bay provinces, respectively. The distinct morphologies are mirrored in distinct, although coupled, flow regimes.

Fast ice has been demonstrated to affect the flow of ice shelves in other locations. Using numerical simulations of the Ward-Hunt Ice Shelf (NW Territories, Canada), MacAyeal and Holdsworth (1986) demonstrated that back stress due to front-fast ice has a perceptible effect on the flow of small ice shelves. A series of Interferometric Synthetic Aperture Radar-driven (InSAR-driven) modeling studies of marine-ice filled rifts at the front of the Ronne Ice Shelf (Hulbe et al., 1998; MacAyeal et al., 1998) led to the conclusion that a mélange of icy material filling shelf-front rifts could be mechanically competent enough to transmit stress from one rift wall to another. Further, those authors suggested that rift-filling marine ice acted as a binding material with a role in shelf-front stability. In both of those cases, marine ice made up a relatively small fraction of the floating ice volume. In the case of the Brunt Ice Shelf, marine ice is a significant fraction of the total ice shelf volume.

Here, a series of numerical experiments are used to study the interplay of marine and meteoric ice in the Brunt Ice Shelf. We employ a thermodynamic model of ice-shelf flow in a domain tailored to the geometries of the three provinces introduced above. The experiments are guided by a high-resolution flow field computed using SAR interferometry and speckle tracking (Joughin, 2002). This pursuit is of interest not only for the insight it yields into this ice shelf system but also in its implications for ice-shelf formation processes along coasts without deep embayments.

\section{Remote Observations of the Brunt Ice Shelf}

\section{ICE RAFT TRACKING}

The large rafts of meteoric ice entrained in the central (ice-raft) province of the Brunt can be tracked using publicly available Moderate Resolution Imaging Spectroradiometer (MODIS) imagery archived at the National Snow and Ice Data Center (Figs. 2 and 3). The resolution of the imagery is $250 \mathrm{~m}$. Cloud cover limits the total number of rafts that can be observed at any particular time. Here, we track five large rafts from 13 August 2000 to 19 February 2003. A surface temperature 


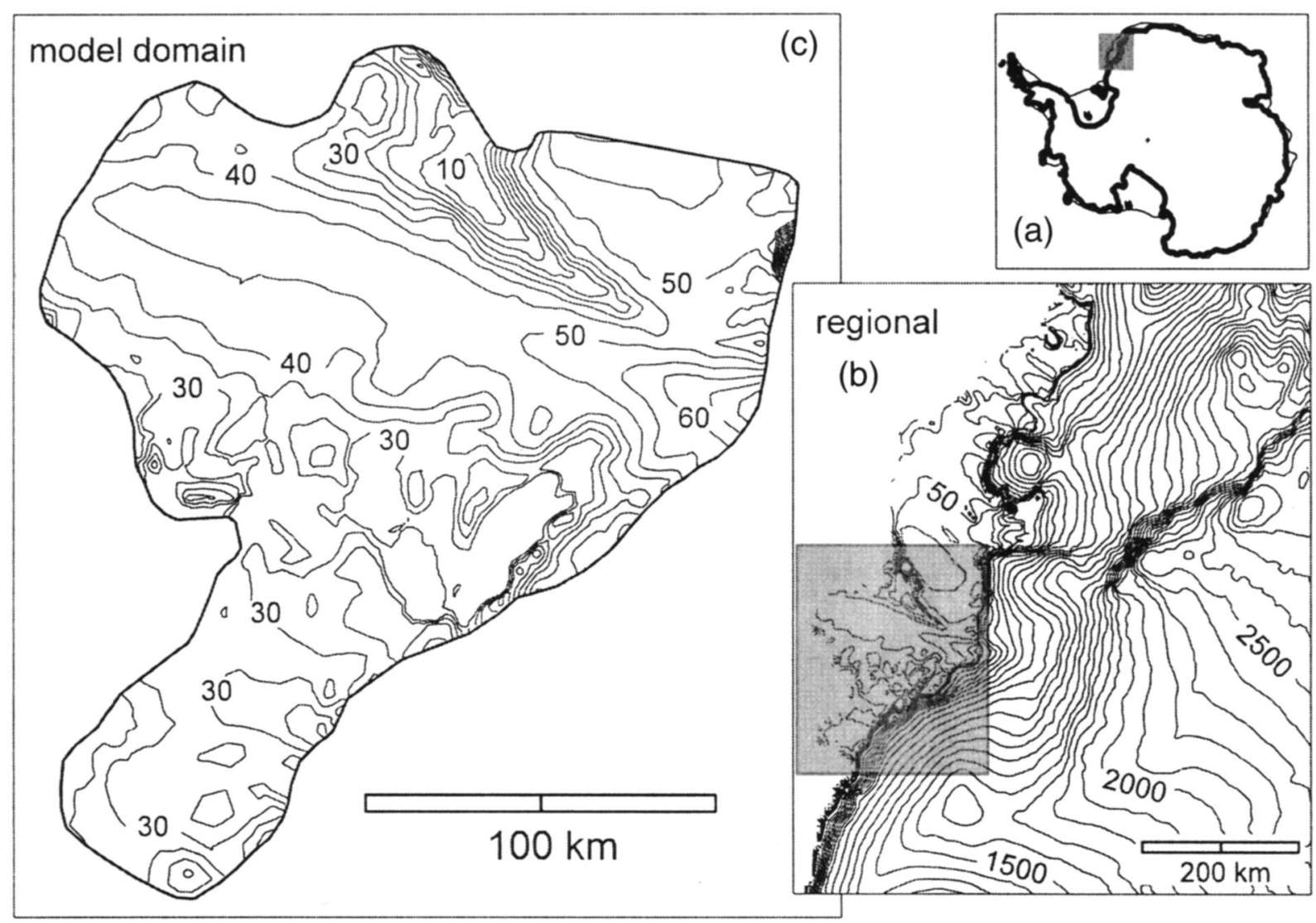

FIGURE 1. Surface elevation of the Brunt Ice Shelf system and adjacent ice sheet. (a) The shelf system is at about $75^{\circ} \mathrm{S}$ latitude, east is to the upper right, and west is to the lower left in this and subsequent figures. In the regional map (b), the contour interval is $100 \mathrm{~m}$ on the grounded ice sheet and $10 \mathrm{~m}$ on floating ice. In the model domain map (c), the contour interval is $5 \mathrm{~m}$. The regional map represents the DEM used in this work, and our interpolation of those data to the model mesh is represented in the model domain map. The grounding line can be identified by the transition from steeply sloping ice sheet edge to gently sloping floating ice shelf surface. The thick StancombWills ice tongue stands out in the eastern region of the shelf, in both the model domain and the regional map.

contrast between marine and meteoric ice makes thermal band images particularly valuable to our analysis of the ice shelf materials. The contrast must be primarily due to differences in provenance, but in some images we also observe extreme cold temperatures at low elevations that must be the result of cold-air ponding in still conditions.

Our primary interest in tracking raft locations is to evaluate the relative deformation rates of marine and meteoric ice. If the rafts move together as a cohort, then the materials must deform at similar rates. Three rafts digitized over the interval appear in all four images (Fig. 3). On the scale and over the time interval of our observation, the rafts maintain positions relative to one another and follow the regional ice-shelf flow field as they advect toward the open ocean. From this, we conclude that the rafts and marine ice within which they are embedded behave as a mechanically connected unit. This assertion is supported by observed ice-shelf velocity, discussed next. What we cannot determine from these observations is which material determines the rate of flow. Their interaction will be investigated in a series of numerical experiments.

\section{ICE VELOCITY AND VELOCITY GRADIENTS}

Surface velocity is computed using SAR interferometry and speckle tracking (Fig. 4a) and methods described by Joughin (2002). The map was derived using fine-beam data acquired from September to November 2000 as part of the Modified Radarsat Antarctic Mapping (MAMM) campaign (Jezek, 2002). The speckle-tracked offsets were smoothed to a resolution of about $2.5 \mathrm{~km}$ so that errors on the grounded ice are in the range of 1 to $2 \mathrm{~m} \mathrm{a}^{-1}$, except in a few of the fast moving areas where they may be slightly higher. These error estimates do not include ionospheric streak errors (Gray et al., 2000), which could increase errors by a few meters per annum at a few isolated locations. On the floating ice, tidal displacements are corrected using an Antarctic tidal model (Padman et al., 2002). The uncertainty in the tidal displacements is assumed to be $10 \mathrm{~cm}$, which yields an additional error of about $1-3 \mathrm{~m} \mathrm{a}^{-1}$ on the ice shelf. When combined, the independent errors produce an error in our computed ice-shelf speeds of $4 \mathrm{~m} \mathrm{a}^{-1}$ or less.

Velocities and their gradients chart the importance of various boundary conditions to the flow of an ice shelf. In general, ice-shelf speed increases toward the seaward front, as the influence of stresses applied at other boundaries decreases. In an embayed ice shelf the result is similarly embayed velocity contours, modest downstream-spreading rates that may plateau near the seaward front, and significant lateral shear-strain rates across the shelf. In an ice tongue, where side drag is nearly zero, longitudinal strain rates are large compared to lateral shearstrain rates, and the geometry of velocity contours should be approximately front-parallel. With these general patterns in mind, several features of the ice shelf's flow (Fig. 4a) draw immediate attention.

First, there is extreme flowline turning in the Halley Bay province of the shelf. This is a consequence of the asymmetric confinement of the ice in this region. Apart from the McDonald ice rumples, no boundaries impede southwestward flow, while to the northeast, flow is confined by the ice-raft province of the shelf. That ice here is not free to spread laterally in both directions implies mechanical competence in the marine-and-meteoric ice to the northeast.

Second, ice speed in the Halley Bay province is very large, from 400 to $1000 \mathrm{~m} \mathrm{a}^{-1}$ in the epoch of the SAR data collection. Longitudinal 


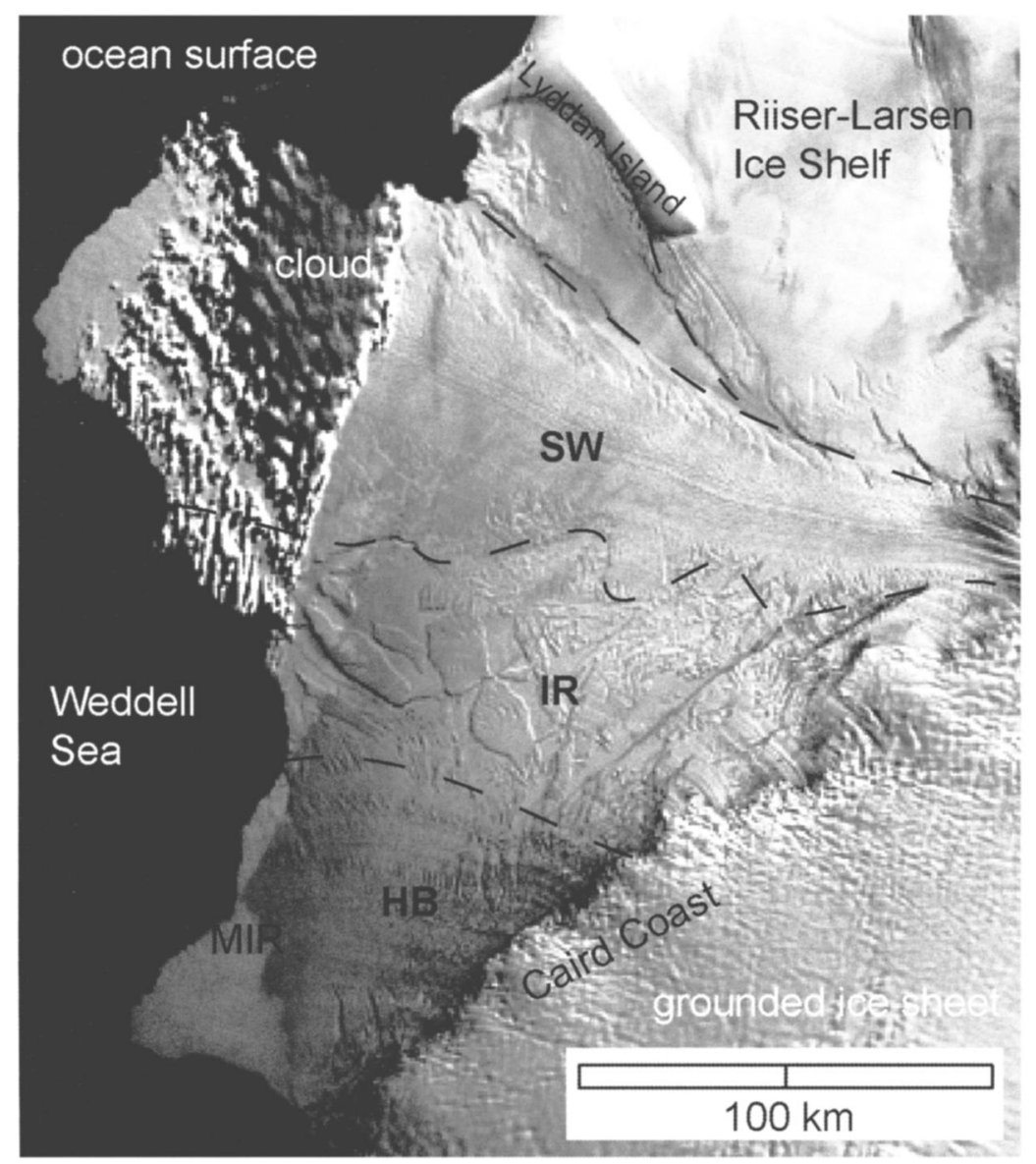

FIGURE 2. Visible band Moderate Resolution Imaging Spectroradiometer (MODIS) image of the Brunt Ice Shelf system, 19 February 2003. The three iceshelf provinces discussed in this paper and other prominent features are labeled. Acronyms are as follows: SW: Stancomb-Wills province; IR: ice raft province; HB: Halley Bay province; and MIR: McDonald ice rumples. In many locations, the edges of thick meteoric ice regions are delineated by shadow.

strain rates are about $0.01 \mathrm{a}^{-1}$, similar to rates on the former Larsen Ice Shelf, a small, fringing Antarctic shelf that was well confined by peninsulas and nunataks (cf. Scambos et al., 2000). In part, the fast flow can be attributed to the lack of confining boundaries for the shelf but may also be due to intermittent connection to the coast associated with rifting due to tension across the grounding line. This would account for the fast flow and relatively modest mid-shelf strain rates.

Third, shear-strain rates along the right-lateral (northeast) edge of the Stancomb-Wills glacier tongue are very large, up to $0.1 \mathrm{a}^{-1}$. Like its left-lateral counterpart, the right lateral margin is marked by marine-ice filled, through-cutting rifts. However, the most striking physical attribute of this margin is not large transverse rifts, but instead a longitudinal, marine-ice filled separation from adjacent Riiser-Larsen Ice Shelf ice that widens downstream, toward Lyddan Island. We interpret this pattern to indicate either relatively little dynamic connection between the ice tongue and other ice eastward of its right-lateral margin or very fast deformation in a narrow band of marine ice along that boundary.

Fourth, velocity gradients in the Stancomb-Wills ice tongue are unusual, when considered within the framework of prototypical ice shelves. While the velocity azimuth follows the thickness gradient (as it should), longitudinal strain rates (azimuth-following gradients of ice speed) are nearly zero along much of the floating ice tongue. Additionally, the asymmetry between the right and left lateral boundaries results in shear-strain rates of the same sign across the entire ice tongue. That is, ice speed is neither fastest at the centerline of the ice tongue nor does it increase toward the front of the ice tongue (once away from the glacier outlet). Instead, ice speed increases in the left-lateral direction, to reach a maximum at the left-lateral (southwest) front of the StancombWills province of the shelf.

The fourth observation can be considered with respect to the dynamic role of marine ice in the ice-raft province of the Brunt Ice Shelf.
Large shear-strain rates at the right-lateral boundary of the ice tongue indicate either relatively weak margin ice due to strain heating or rotation of crystal axes near the glacier outlet, or a relatively weak connection to the marine ice filling right-lateral rifts. Were the left-lateral boundary of the ice tongue similarly weak, the ice would flow more in the manner of an unconfined ice tongue. Instead, ice at the left-lateral boundary provides resistance to the driving stress, distributing it over a relatively wide region. The marine ice is not stiff enough to provide coast-like resistance, which would result in a narrow shear margin, but it does transmit stress, in effect allowing the Caird Coast (the Halley Bay province coastline) to balance some portion of the ice tongue's driving stress. Thus, despite the comparatively great thickness and fast flow of the ice tongue, the kinematic front of the ice-shelf complex is near its geometric center, where the floating ice mass is a mixture of materials.

We will test the above interpretation of the role of marine ice in the Brunt Ice Shelf by attempting to replicate the flow patterns using a numerical model of ice shelf flow. Our goal is not to reproduce the flow precisely, but instead to test the validity of the simple set of interpretations outlined above. Our fundamental assertion is that marine ice is well-connected to the surrounding meteoric ice and acts to dissipate gravitational potential energy. A consequence of that connection is to create a dynamically coherent ice shelf out of three, morphologically (and presumably rheologically) distinct floating ice masses. This framework may have implications for the seaward expansion of ice shelves in regions where pinning points are scarce.

\section{Numerical Experiments}

\section{THE MODEL}

Precise simulation of this system is not possible with a typical iceshelf model (cf. MacAyeal et al., 1996). The two main obstacles are the 


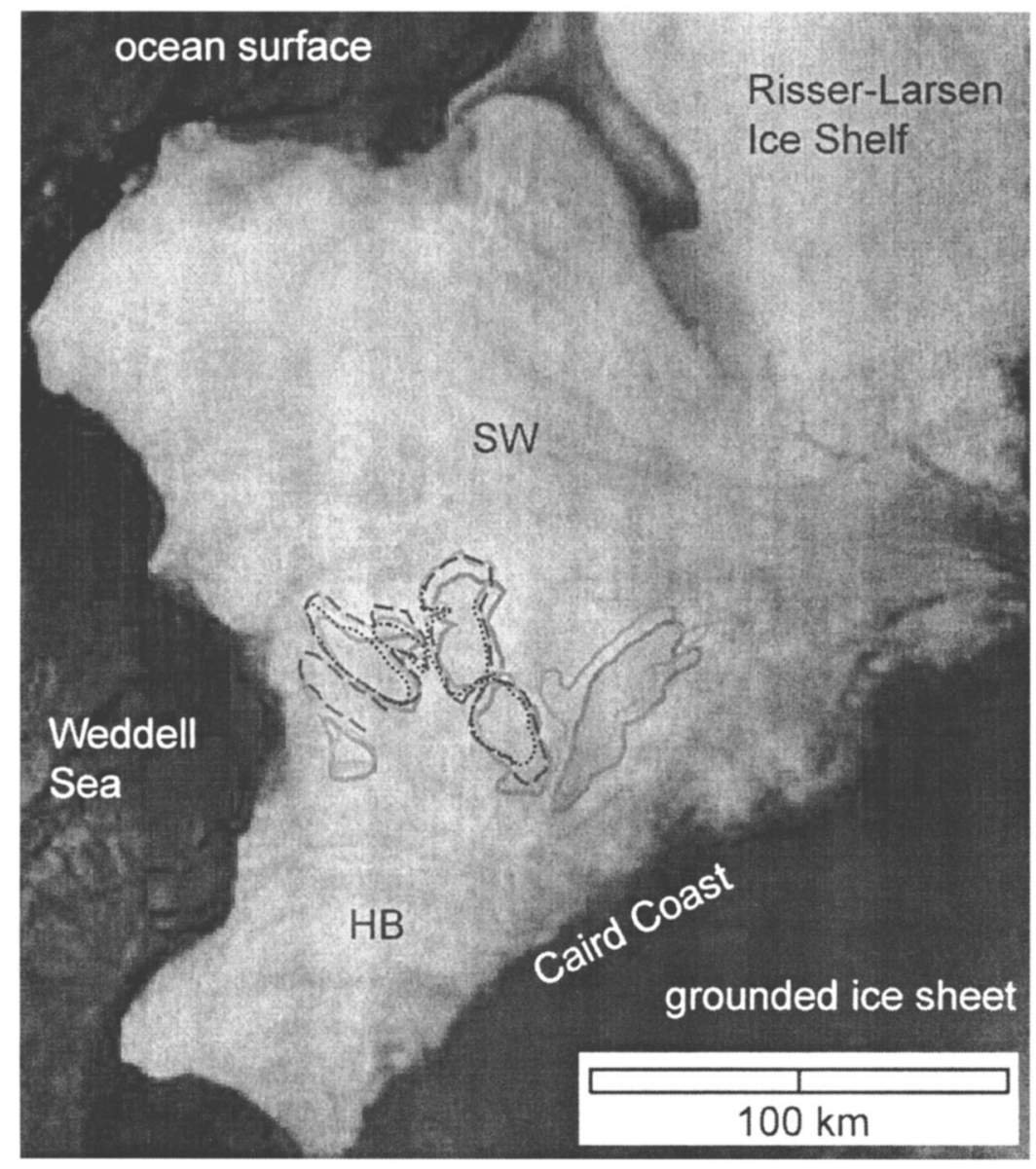

FIGURE 3. Thermal band MODIS image of the same area in Figure 2, 13 August 2000. Large rafts of meteoric ice in the central region of the Brunt Ice Shelf are tracked using publicly available MODIS images archived at the National Snow and Ice Data Center. Digitized raft boundaries shown here are from 13 August 2000 (solid dark grey), 30 August 2001 (solid light grey), 15 September 2002 (dashed black), and 19 February 2003 (dotted black).

non-homogeneous nature of the shelf and an unpredictable timedependence in some coastal stress boundary conditions. Both meteoric and marine ice make up significant portions of the ice volume, and the different materials certainly require different flow laws. The non homogeneity can be treated simplistically with imposed spatial variations in a flow law rate factor, but an additional problem is that the rafts and rifts advect, making any such imposed variations timedependent. Additionally, large, through-cutting rifts open along the grounding line in both the Halley Bay and ice-raft provinces. Over time, marine ice grows to fill the rifts, but near the grounding line, the dynamic connection between shelf and land is time-dependent as well. However, we can rely on three straightforward points to make use of a relatively simple model:

(1) Through most of the shelf, the marine ice appears to be thick. Surface elevation derived from radar altimetry (Bamber and Bindschadler, 1997), indicates marine ice about $100 \mathrm{~m}$ thick surrounding thicker ice rafts and filling large rifts (according to floatation; Fig. 1). Internal stresses will drive the deformation of this thick ice (Kreyscher et al., 2000), and we may reasonably neglect typical sea-ice flow complications such as pressure ridge formation. (Snow ramps at the edges of ice rafts may bias this measurement, so we investigate the consequences of overestimating marine ice thickness in the numerical experiments to follow.)

(2) The observed velocity field implies that through much of the ice shelf system, stress is transmitted between marine and meteoric ice. This connection is also noted by Rignot (2002), who reports that interferometric fringes are continuous across ice-raft to marine-ice boundaries.

(3) We can limit our view to be an instantaneous one, at an epoch for which accurate ice surface elevation is available. In so doing, we enable ourselves to distinguish between marine and meteoric ice (via its freeboard) and thereby define regions of the model domain with differing ice properties.

With these conditions in mind, we employ a traditional ice-shelf flow model to compute instantaneous velocity in the Brunt Ice Shelf system for a series of assumptions about the relative stiffness and thickness of the marine and meteoric ice. Our goals are twofold: to investigate how rheological discontinuities affect the flow of the ice shelf, and to investigate the importance of the marine ice to the dynamics of the whole Brunt Ice Shelf system.

The ice shelf model derives from the more complete ice sheet model presented by Hulbe and MacAyeal (1999). Ice flow is described by a set of stress balance equations, simplified by the assumption that horizontal flow is depth independent. The typical flow law for glacier ice, with an exponent of 3 , is used. The flow-law rate factor is nonhomogenous, as discussed below. The stress balance equations are derived (MacAyeal and Thomas, 1982) using the dynamic boundary conditions of a stress-free top surface, a zero shear-stress basal boundary, and a depth integrated sea-water pressure applied along the seaward front of the ice shelf. For example, stress-balance in the $x$ direction of a Cartesian coordinate system with $x$ - and $y$ - axes in the horizontal plane is written:

$$
\frac{\partial}{\partial x}\left(2 v_{\mathrm{e}} h\left(2 \frac{\partial u}{\partial x}+\frac{\partial v}{\partial y}\right)\right)+\frac{\partial}{\partial y}\left(v_{\mathrm{e}} h\left(\frac{\partial u}{\partial y}+\frac{\partial v}{\partial x}\right)\right)-\rho g h \frac{\partial z_{\mathrm{s}}}{\partial x}=0,
$$

where $u$ and $v$ represent horizontal velocity in the $x$ - and $y$-directions, respectively, $h$ represents the ice thickness, $\rho$ represents ice density, $g$ represents acceleration due to gravity, $z$ s represents elevation of the upper surface, and $v_{e}$ represents the effective viscosity of the ice, described below. The first term in Equation 1 describes longitudinal 

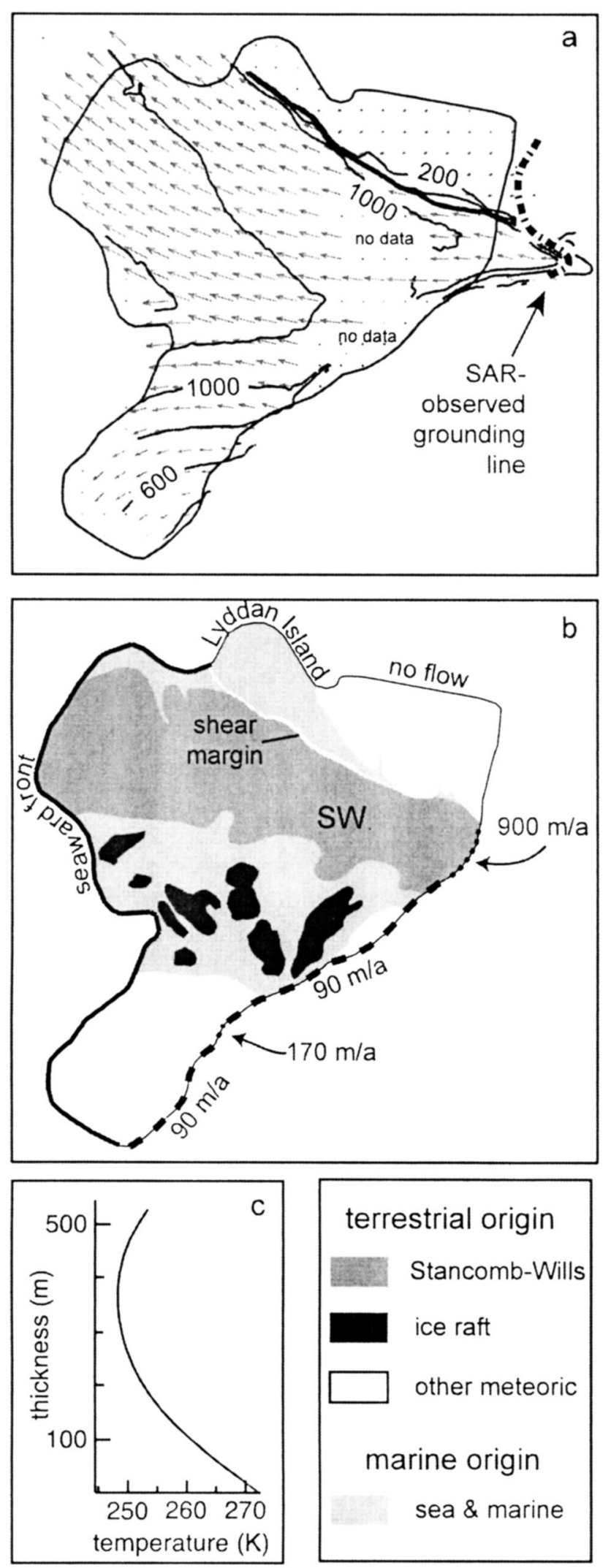

FIGURE 4. Observed ice shelf velocity and model domain. (a) Map of observed surface velocity, magnitude, and azimuth. The contour interval is $200 \mathrm{~m} \mathrm{a}^{-1}$. (b) Model domain and classified ice types. The heavy solid line indicates the seaward front of the shelf. Heavy dashed lines indicate ice-sheet inflow, and heavy dotted lines indicate glacier inflows. A legend at the lower right describes our classifications of ice derived from land (darker grays and strain rates. The second term describes horizontal shear-strain rates. The third term, involving ice thickness and the surface elevation gradients, describes the pressure gradient due to gravity. The simplifying assumption, that horizontal flow is depth-independent, is valid as long as the vertical length scale of the ice is much smaller than the horizontal length scale. The constitutive relation between stress and strain is embodied by an effective viscosity, $v_{\mathrm{e}}$, using Glen's flow law for ice and the assumption of incompressibility. It is defined using a depth-average rate factor, $\bar{B}$, and the flow-law exponent, $n$ :

$$
v_{\mathrm{e}}=\frac{\bar{B}}{2\left[\left(\frac{\partial u}{\partial x}\right)^{2}+\left(\frac{\partial v}{\partial y}\right)^{2}+\frac{1}{4}\left(\frac{\partial u}{\partial y}+\frac{\partial v}{\partial x}\right)^{2}+\frac{\partial u}{\partial x} \frac{\partial v}{\partial y}\right]^{\frac{n-1}{n}}} .
$$

Our estimate of $\bar{B}$ is discussed in more detail below. The stress balance equations are solved by iteration on the effective viscosity. The model infrastructure has been tested according to the European Ice Sheet Modelling Initiative standards (MacAyeal et al., 1996).

Special conditions are applied to Equation 1 at two types of boundaries. First, a no-slip condition is specified at coastal no-flow boundaries. Second, the basal stress boundary condition is modified to simulate the effect of basal traction at the McDonald ice rumples by incorporating into the stress balance a basal stress term that is the product of the horizontal velocity and a (scalar) friction parameter (the friction parameter is set to $10^{-8} \mathrm{~Pa} \mathrm{~s}$, an order of magnitude smaller than the Ross ice-stream value suggested by MacAyeal et al., 1995; cf. Hulbe and MacAyeal, 1999).

The governing equations are represented by piecewise linear functions on a finite element mesh that embodies the geometry of the floating ice shelf. Mesh resolution varies, in order to represent large rifts and ice rafts within the shelf system. The mesh contains 6020 nodes and 11,790 elements. The mean element area is $2.5 \mathrm{~km}^{2}$. Within the model domain, we identify subregions of various ice types (Fig. 4). The boundaries derive from a combination of digitizations of features observed in MODIS images and changes in surface elevation. The classification allows us to easily manipulate the value of $\bar{B}$ throughout the model domain.

Surface elevation is interpolated to the model mesh using Bamber and Bindschadler's (1997) data set. This DEM was selected because it resolves boundaries between relatively high elevation meteoric ice surfaces and relatively low elevation sea ice surfaces. Surface elevation must be adjusted at mesh nodes within the meteoric ice rafts where there is a discrepancy between model ice-raft edges and those indicated by the interpolated surface elevation. In order to automate this process, we replace ice thickness within each raft uniformly, at a value equal to the $80 \%$ of the maximum ice thickness in the raft. The result is the removal of a few thin patches within each model ice raft. Ice thickness is computed according to floatation.

\section{FLOW-LAW RATE FACTOR}

The model must account for spatially heterogeneous rheology. In an ideal situation, the surface velocity, along with ice shelf geometry, could be inverted to determine the rate factor. However, in this case, accurate and complete measurements of those two quantities are

white) and new ice growing at or near the sea surface (lightest gray). The narrow white band along the right-lateral side of the Stancomb-Wills ice tongue labeled shear margin is classified as very fast-shearing ice. (c) An estimated temperature profile near the grounding line of the Stancomb-Wills ice tongue. Elsewhere, ice flows more slowly toward the shelf, with the result that middepth ice is not as cold and the basal temperature gradient is not as steep as the $T(z)$ plotted here. 

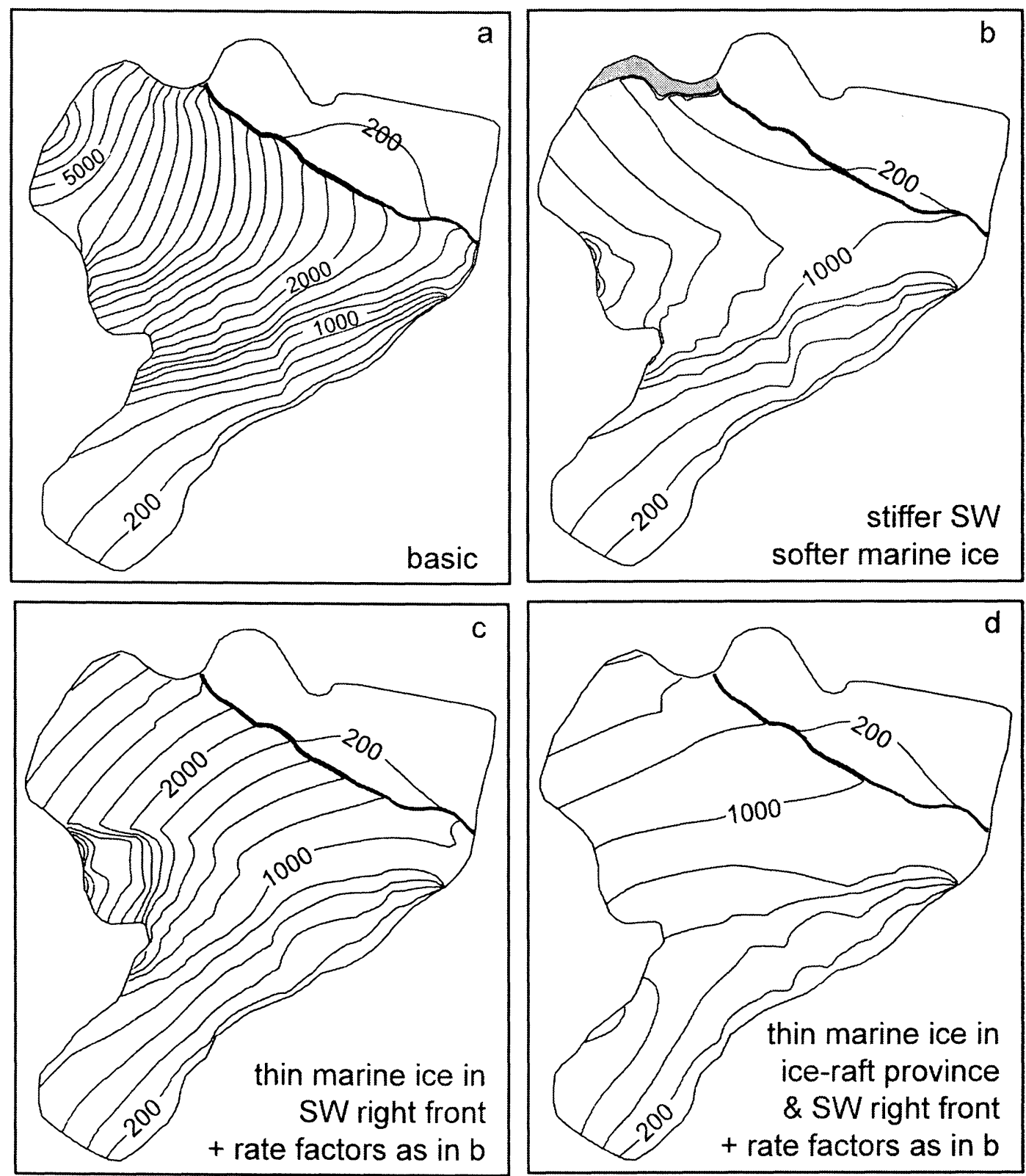

FIGURE 5. Numerical simulations of ice shelf flow with several assumptions about ice softness. In all panels, the contour interval is $200 \mathrm{~m} \mathrm{a}^{-1}$. (a) Standard simulation; the rate factor depends only on the estimated ice temperature, except in the right-lateral shear margin of the Stancomb-Wills ice tongue, where its value is reduced by a factor of 10 . Ice speeds are much too fast, and velocity gradients do not match the observed flow pattern. (b) Significant manipulation of the rate factor, in order to increase the contrast between the ice tongue and surrounding marine ice: $\times 4$ in Stancomb-Wills ice, $\times 0.5$ in marine ice along the eastern front of the Stancomb-Wills, $\times 0.8$ in marine ice in the ice-raft province west of the Stancomb Wills, $\times 1.5$ in all ice rafts, $\times 1.4$ in meteoric ice east of Stancomb-Wills, and $\times 0.9$ in the Halley bay province of the shelf. (c) An experiment to test the effect of thinning near-front ice; all manipulations of the rate factor are as in panel b, except for the marine ice at the eastern front of the ice tongue, which is thinned to $50 \mathrm{~m}$ instead of softened. (d) Another marineice thinning experiment; all manipulations of the rate factor are as in Figure 5c, except marine ice at the eastern front of the ice tongue and in the ice-raft province are thinned to $50 \mathrm{~m}$ instead of softened.

made in significantly different epochs, so an inverse calculation is not possible. Here, we adopt a forward view and the typical flow law for glacier ice, and impose simple spatial variations in the flow-law rate factor. A spatially variable flow law would be more correct, but for the broad-scale goals of the present work, the simpler approach is efficient. The flow-law rate factor is specified using a two-step process. First, we estimate ice-shelf temperature (Appendix A) and use the spatially variable temperature to compute a depth-average rate factor at each model node. Second, we manipulate the rate factor with a scalar multiplier. The multiplier allows us to tune the rate factor in order to compensate for inaccuracy in our temperature estimate and is a means by which to enhance the contrast between ices of different origins (for example, meteoric ice rafts and the marine ice in which they are embedded) for the purpose of numerical experimentation. Our imposed changes are described in the caption to Figure 5. Salinity may enhance softness of the marine ice, although salinity is observed to decrease exponentially with sea ice floe thickness (Kovacs, 1996). A relatively large multiplier is used to reproduce the fast shearing between the right-lateral margin of the Stancomb-Wills ice tongue and slowflowing ice to the east of that kinematic boundary. 


\section{Model Experiments}

Many experiments were conducted to investigate the importance of rate-factor and ice-thickness contrasts between marine and meteoric ice to ice shelf flow. Flow fields from several particularly informative experiments are discussed here (Fig. 5). We cannot expect to reproduce the observed flow field exactly because our model geometry differs from the ice-shelf geometry at the time of the SAR data collection and because we have simplified both the geometry and the rheology of the ice shelf system. Nevertheless, correctly specified contrasts between relatively stiff and relatively soft, or relatively thick and relatively thin, ice should be able to reproduce the general pattern of flow (that is, the velocity gradients).

Our experiments produce two distinct flow patterns (Fig. 5). In one, marine ice west of the Stancomb-Wills ice tongue has little influence on its flow, and large downstream velocity gradients result in the fastest ice flow at the front of the ice tongue (Figs. 5a, c, and d). In the other flow pattern, marine ice west of the ice tongue does affect its flow, and produces relatively small downstream velocity gradients and the fastest flow is produced near the center of the Brunt Ice Shelf complex (Fig. 5b). The latter pattern is a good simulation of the observed flow pattern. In all but one experiment, we manipulate the initial $B$ estimated by softening marine ice and stiffening meteoric ice.

The right-lateral margin of the Stancomb-Wills ice tongue requires special treatment in order to correctly simulate the large shear-strain rates observed at the boundary between the ice tongue and rift-filling marine ice to its east. The fast shearing margin is represented by an order-of-magnitude reduction in the value of $\bar{B}$ in a thin band along the material boundary. This relatively large modification of the rate factor is made in all four experiments represented in Figure 5. The manipulation is consistent with either a poor connection between the materials or a very weak marine ice band attached to the ice tongue. If the former interpretation is correct, it is in striking contrast to the connection between marine and meteoric ice elsewhere in the ice shelf system.

The observed flow pattern in the Stancomb-Wills ice tongue is well reproduced only when marine ice in a narrow strip along its eastern front is weakened (Fig. 5b). This flow pattern is not obtained when this ice is thinned (Fig. 5c) instead of softened. A similar experiment, in which marine ice in the ice-raft province west of the ice tongue is also thinned, also yields poor results (Fig. 5d). Were the thinice scenarios to provide better simulations than the soft-ice scenario, the implication would be that marine ice is largely irrelevant to the flow of the ice shelf. However, we find the opposite. By deforming rapidly, the near-front marine ice dissipates significant gravitational potential energy. The marine ice allows Lyddan Island, to which it is also mechanically attached, to resist the driving stress.

Marine ice in the ice-raft province also plays an important role in the stress balance of the Brunt Ice Shelf system. It provides a dynamic connection between the western meteoric ice and adjacent Caird Coast, and the far eastern reaches of the shelf. As noted before, were this ice to be irrelevant to shelf flow, thinning it (Fig. 5d) would provide a better simulation of ice shelf flow than experiments in which the marine ice is assumed to have the thickness inferred from satellite altimetry. A range of marine ice thickness and softness combinations could also simulate the observed flow pattern. This does not detract from our fundamental conclusion, that the marine ice plays an important role in the stress balance of the ice shelf system. It is also worth noting that the marine ice flow is moderated by the presence of relatively stiff ice rafts; it flows several times too fast when the stiffness contrast between the two materials is reduced.

Ice speed near the grounding line of the Halley Bay province is observed to increase almost as a step function, within a few kilometers of the grounding line. This is likely the result of fast deformation of new, thin sea ice within rifts and new rift opening at that boundary. Neither process is represented in the model. Thus, while our simulations reproduce the large left-lateral flowline turning due to a lack of confinement in that direction, they underestimate ice speed. The experiment in which the contrast between rate factors in marine and meteoric ice is accentuated (Fig. 5b) best reproduces the observed flow pattern, reinforcing the idea that this contrast governs many aspects of ice shelf flow.

\section{Discussion}

The role of marine ice in the Brunt Ice Shelf is twofold. First, its rapid deformation dissipates gravitational potential energy. Second, because it does transmit stresses, it provides a dynamic connection for ice throughout the shelf, allowing a relatively long section of the Caird coastline to act as a confining bay wall for the entire Brunt system. That this takes place is evident in the observed flow pattern: the kinematic center of the shelf is near the geometric center of the whole shelf complex, not at the front of the Stancomb-Wills ice tongue. This point is reinforced by the numerical experiments presented here.

The role of marine ice in the Brunt Ice Shelf may have implications for the expansion phase of coastal (that is, not embayed) ice shelves elsewhere. Meteoric ice from fast-discharging outlet glaciers may nucleate coastal shelves, but in locations where pinning points are few, it would be difficult for such floating ice to expand beyond the geometry of an ice tongue. However, in a sufficiently cold climate, fast ice may grow and persist between several ice tongues, or between an ice tongue and a distant coast. Further thickening may occur by basal accretion as cool, fresh meltwater generated beneath adjacent, thick meteoric ice refreezes. The dynamic connection afforded by the thick marine and sea ice mixture could stabilize a growing shelf, allowing it to expand farther seaward than would an unsupported ice tongue. Such interaction between marine and meteoric ice could help explain the apparent expansion of Arctic Ocean ice shelves far from their coastal provenance during northern hemisphere glaciations (Polyak et al., 2001).

\section{Acknowledgments}

C. Hulbe's work was supported by NSF grant OPP-0125754. R. Johnston's work was supported by NASA grant NAG5-11309. I. Joughin performed his contribution to this work at the Jet Propulsion Laboratory, California Institute of Technology, under contract with NASA. The data archival project was supported by NASA grant NAG5-11308 to T. Scambos. We are grateful for animated conversations with $\mathrm{R}$. Thomas about the Brunt Ice Shelf area and a thoughtful review by S. Anderson.

\section{References}

Bamber, J. L., and Bindschadler, R. A., 1997: An improved elevation data set for climate and ice sheet modelling: validation with satellite imagery. Annals of Glaciology, 25: 439-444.

Bombosch, A., and Jenkins, A., 1995: Modelling the formation and deposition of frazin ice beneath Filchner-Ronne Ice Shelf. Journal of Geophysical Research, 100: 6983-6992.

Gray, A. L., Mattar, K. E., and Sofko, G., 2000: Influence of ionospheric electron density fluctuations on satellite radar interferometry. Geophysical Research Letters, 27(10): 1451-1454.

Hulbe, C. L., and MacAyeal, D. R., 1999: A new numerical model of coupled inland ice sheet, ice stream, and ice shelf flow and its application to the West Antarctic Ice Sheet. Journal of Geophysical Research, 104: 25349-25366.

Hulbe, C. L., Rignot, E., and MacAyeal, D. R., 1998: Comparison of ice-shelf creep flow simulations with ice-front motion of FilchnerRonne Ice Shelf, Antarctica, detected by SAR interferometry. Annals of Glaciology, 27: 182-186.

Jezek, K. C., 2002: RADARSAT-1 Antarctic Mapping Project: change-detection and surface velocity campaign. Annals of Glaciology, 34: 263-268. 
Joughin, I., 2002: Ice-sheet velocity mapping: a combined interferometric and speckle-tracking approach. Annals of Glaciology, 34: 195-201.

Kovacs, A., 1996: Sea ice: Part I. Bulk salinity versus ice flow thickness. Cold Regions Research and Engineering Laboratory Report 96-7, 17 pp.

Kreyscher, M., Harder, M., Lemke, P., and Flato, G. M., 2000: Results of the sea ice model intercomparison project: evaluation of sea ice rheology schemes for use in climate simulations. Journal of Geophysical Research, 105: 11299-11320.

MacAyeal, D. R., and Holdsworth, G., 1986: An investigation of low-stress ice rheology on the Ward-Hunt Ice Shelf. Journal of Geophysical Research, 91: 6347-6358.

MacAyeal, D. R., and Thomas, R. H., 1982: Numerical modelling of ice shelf motion. Annals of Glaciology, 3: 189-193.

MacAyeal, D. R., Bindschadler, R. A., and Scambos, T. A., 1995: Basal friction of Ice Stream E, West Antarctica. Journal of Glaciology, 41(138): 247-262.

MacAyeal, D. R., Rommelaere, V., Huybrechts, P., Hulbe, C. L., Determann, J., and Ritz, C., 1996: An ice-shelf model test based on the Ross Ice Shelf. Annals of Glaciology, 23: 46-51.

MacAyeal, D., Rignot, E., and Hulbe, C., 1998: Ice-shelf dynamics near the front of Filchner-Ronne Ice Shelf, Antarctica, revealed by SAR interferometry: model/interferogram comparison. Journal of Glaciology, 44: 419-428.

Padman, L., Fricker, H. A., Coleman, R., Howard, S., and Erofeeva, L., 2002: A new tide model for the Antarctic ice shelves and seas. Annals of Glaciology, 34: 247-254.

Polyak, L., Edwards, M. H., Coakley, B. J., and Jakobsson, M., 2001: Ice shelves in the Pleistocene Arctic Ocean inferred from glaciogenic deep-sea bedforms. Nature, 410: 453-457.

Rignot, E., 2002: Mass balance of East Antarctic glaciers and ice shelves from satellite data. Annals of Glaciology, 34: 217-227.

Sanderson, T. J. O., 1979: Equilibrium profile of ice shelves. Journal of Glaciology, 22: 435-460.

Scambos, T. A., Hulbe, C. L., Fahnestock, M. A., and Bohlander, J., 2000: The link between climate warming and ice shelf breakups in the Antarctic Peninsula. Journal of Glaciology, 46(154): 516-530.

Thomas, R. A., 1973: The dynamics of the Brunt Ice Shelf, Coats Land, Antarctica. Scientific Reports-British Antarctic Survey, 79, 45 pp.

Thomas, R. A., 1979: Ice shelves: a review. Journal of Glaciology, 24: 273-286.

Vaughan, D. G., Bamber, J. L., Giovinetto, M., Russell, J., and Cooper, A. P. R., 1999: Reassessment of net surface mass balance in Antarctica. Journal of Climate, 12(4): 933-946.

Revised ms submitted March 2005

\section{Appendix A}

Typically, an estimate of ice shelf temperature would be generated by initializing the modeled ice with some temperature field, specifying boundary temperatures for the upper surface, base, and ice-sheet inflows, and iterating on either a set of heat balance equations until a steady-state temperature distribution is reached or a set of coupled heat-balance and stress-balance equations until the modeled flow field replicates the observed flow field (e.g., Scambos et al., 2001). Such an approach is not possible in the present case because it assumes a relatively uniform material and simple, rift-free geometry. Neither assumption is valid here. However, transit times through the Brunt Ice Shelf are relatively short, about 50 years through the Stancomb-Wills province and 20 years through the Halley Bay province. The mismatch between fast advection and relatively slow thermal diffusion allows us to assume that the temperature of ice flowing into the shelf is little modified during its transit through the shelf, expect perhaps near boundaries with materials of different temperatures, where horizontal diffusion could be significant. Thus, we estimate the temperature of ice flowing into the shelf from the grounded ice sheet, allow an appropriate adjustment to the change in basal temperature upon going afloat, and use the result to compute the rate factor in the flow law in our ice-shelf model. Recalling that we are interested in rheologic contrasts and will manipulate the rate factor in order to enhance such contrasts in the model, our goal here is a reasonable estimate from which to base our numerical experiments.

Temperature in the ice sheet is estimated by tracking depthdependent thermal evolution along particle paths from the interior to the grounding line. Temperature profiles are initialized under the assumption of steady state and then advected toward the grounding line with boundary conditions on the surface accumulation rate (from Vaughan et al., 1999), ice surface temperature (from the data of Comiso, 1994), and a geothermal flux of $0.065 \mathrm{~W} \mathrm{~m}^{-2}$. Advective speed comes from the SAR-derived velocity field (Fig. 4), and we limit the calculation to where the surface speed indicates significant basal sliding. Ice temperature is updated along the advective path according to a vertical heat balance:

$$
\frac{\mathrm{D} T}{\mathrm{D} t}=-w \frac{\partial T}{\partial z}+\frac{k_{i}}{\rho c} \frac{\partial^{2} T}{\partial z^{2}}+\frac{W}{\rho c},
$$

in which $T$ represents the temperature at any depth, $w$ represents ice motion in the vertical $(z)$ direction, $k_{i}$ represents the thermal conductivity of ice $\left(3.1 \times 108 \mathrm{~W} \mathrm{~m} \mathrm{~K}^{-1}\right), W$ represents heat generated by vertical shear strain within the ice, $\rho$ represents the ice density $(910 \mathrm{~kg}$ $\left.\mathrm{m}^{-3}\right)$, and $c$ represents the heat capacity of ice $\left(2009 \mathrm{~J} \mathrm{~kg}^{-1} \mathrm{~K}^{-1}\right)$. It is assumed, reasonably, that horizontal temperature diffusion is small. The vertical velocity varies linearly from the local ice-equivalent accumulation rate at the surface to the basal melting (or freezing) rate. The latter is computed according to heat balance at the ice/bed interface (see Hulbe and MacAyeal, 1999). The depth-varying value of $W$ is computed using the typical assumption for ice-sheet flow, that the gravitational driving stress is balanced locally by basal shear stress (see Hulbe and MacAyeal, 1999, for more detail). The validity of Equation A1 depends on the relative magnitudes of sliding and deformation speeds. This is the case because the formulation assumes that the vertical gradient in horizontal advection, which causes cold surface ice to advect downstream more rapidly than warm ice at depth, is unimportant compared to the total downstream advection rate. Our calculation begins about $175 \mathrm{~km}$ upstream of the grounding line, a location at which we estimate the deformation speed to be about half the observed surface speed. Thus, in the upstream part of the flowline, we advect the deepest ice downstream about $50 \%$ too fast, but the error decreases as the sliding speed increases with distance downstream (from about $40 \mathrm{~m} \mathrm{a}^{-1}$ to about $900 \mathrm{~m} \mathrm{a}^{-1}$ at the grounding line). The ice sheet geometry is assumed to be at steady state, so that:

$$
\frac{\mathrm{D} h}{\mathrm{D} t}=\hat{u} \frac{\partial h}{\partial \hat{x}},
$$

in which $\hat{x}$ is the flow-following horizontal coordinate, $\hat{u}$ represents the advective speed at any $t$, and $h$ represents ice thickness. More detail about the lagrangian calculation is in Hulbe and Fahnestock (in press). In marine ice, we assume a linear temperature profile between the upper surface and a salinity-adjusted melt temperature at the base. This approximation is reasonable, as the ice grows in place, presumably in equilibrium with local conditions.

Our estimated temperature profile at the Stancomb-Wills Glacier grounding line is plotted in Figure 4c. The profile is distinctive for its negative gradient in near-surface ice and large positive gradient at depth. This result is very similar to Dahl-Jensen's (1989) flowline calculations. 